\title{
Facilitative effect of a pretest exposure to the CS: Analysis and implications for the memory trace
}

\author{
PASCALE GISQUET-VERRIER and TATIANA ALEXINSKY \\ Centre National de la Recherche Scientifique, Gif sur Yvette, France
}

\begin{abstract}
Retention of a brightness discrimination avoidance task by rats is impaired (Kamin effect) following a 1-h training-to-test interval (TTI), is enhanced after a 3-day TTI (reminiscence, or longterm spontaneous improvement), and is disrupted following a 21-day TTI (long-term forgetting). An exposure to the conditioned stimulus (CS), delivered $5 \mathrm{~min}$ before a 1-h delayed retention test, not only compensated for the performance deficit that corresponds to the Kamin effect, but induced a large improvement in performance similar to that normally obtained after a 3-day TTI. It can be proposed that such cuing may act either by accelerating a natural memory-trace maturation process or by improving the retrievability of the memory trace. Since these possibilities lead to opposite predictions concerning the length of the facilitation induced by cuing, the effect of a pretest exposure to the CS on performance obtained during a 1-h delayed retention test was studied after several cuing-to-test intervals $(0,5,10$, or $20 \mathrm{~min})$. The results, which indicate that cuing transiently enhanced subsequent retention performance, more convincingly support the retrieval hypothesis. The effects of pretest exposure to the CS (which occurred 5 min before testing) were also examined $10 \mathrm{~min}, 1 \mathrm{~h}$, or $24 \mathrm{~h}$ after initial training. The results indicate that the facilitative effect of cuing obtained when retention performance was disrupted shortly after training (1-h TTI) was also obtained after a 24-h retention interval, in the absence of performance disruption. An interpretation of the facilitative effect of a pretest exposure to the CS is proposed, and implications concerning the memory trace are further discussed in relation to the multidimensional hypothesis.
\end{abstract}

In previous research, we have shown that following partial mastery of a brightness discrimination motivated by shock, retention performance varies as a multiphasic function of the training-to-test interval (TTI). Relative to the end of training, a deterioration of performance occurred when testing took place $1 \mathrm{~h}$ after initial acquisition (Kamin effect). A long-term spontaneous improvement of performance (LTSI, or reminiscence) was observed after a 3day retention interval, and a deterioration of retention performance (long-term forgetting) was obtained after 21 days (Gisquet-Verrier \& Alexinsky, 1988; see also Huppert \& Deutsch, 1969; Kamin, 1957).

In a recent paper, the effects of nine pretest cuing treatments were studied during these three particular retention intervals (Gisquet-Verrier, Dekeyne, \& Alexinsky, 1989). Although none of the cuing treatments was able to further enhance retention performance during LTSI, pretest exposure to some training events was highly effective in alleviating the performance deficits obtained after either an intermediate retention interval (Kamin effect) or an extended retention interval (long-term forgetting). It was further shown that the effectiveness of a particular cuing treatment varied as a function of the length

Correspondence may be addressed to Pascale Gisquet-Verrier, Département de Psychophysiologie, LPN2, C.N.R.S., 91190 Gif sur Yvette, France. of the TTI. Furthermore, the relative effectiveness of the components of the original training episode as pretest cues differed according to whether the performance deficit resulted from a short or a long time interval. The most effective pretest cues in overcoming a performance deficit resulting from long-term forgetting were provided by exposure to the experimental context or to a well-ordered sequence of training events (see also Deweer, Sara, \& Hars, 1980; Gatti, Pais, \& Weeks, 1975; Gisquet-Verrier \& Alexinsky, 1986). On the other hand, 1 h after the training phase, exposure to the conditioned stimulus (CS) markedly enhanced the otherwise depressed retention performance (see also Rohrbaugh, Riccio, \& Arthur, 1972).

However, pretest exposure to the CS $1 \mathrm{~h}$ after initial training not only compensated for the performance deficit obtained in noncued animals, but induced a real enhancement of performance relative to the level reached at the end of training, one at least as large as that spontaneously obtained after a 3-day retention interval (Gisquet-Verrier et al., 1989). Two general hypotheses can explain the facilitative effect of a pretest exposure to the CS shortly after training. First, it can be proposed that cuing accelerates a maturation process (consolidation-like process) that normally takes 3 days. Second, one may suggest that cuing acts in the same way as it does long after training-that is, by enhancing the retrievability of an already mature memory trace. Using the same task, we have demonstrated that following long-term forgetting, the effectiveness of 
some cuing treatments did not persist longer than $10 \mathrm{~min}$ (Gisquet-Verrier \& Alexinsky, 1987). Hence, it appears that, in our conditions, when cuing acts on retrieval processes, its effectiveness is quite transient. Alternatively, if cuing delivered shortly after training accelerates the natural maturation process, a longer lasting effect would be expected. Therefore, the first aim of the present study was to determine how long the cuing effect lasts. To answer that question, the length of time between the end of cuing and the beginning of testing (the cuing-to-test interval) was varied in rats tested $1 \mathrm{~h}$ after initial acquisition. Apart from the noncued group, other groups were tested immediately, 5,10 , or $20 \mathrm{~min}$ after cuing.

A third account of the improvement of performance induced by a pretest exposure to the CS is that the facilitative effect obtained $1 \mathrm{~h}$ after training may be specific to the particular causes (the animal's internal state, for instance) of the transitory drop of performance (the Kamin effect). According to this possibility, cuing effectiveness would be restricted to the 1 -h retention interval. On the other hand, a facilitative effect of a pretest exposure to the CS would still be predicted by the two previous hypotheses (maturation or retrieval) following any retention interval shorter than 3 days. Gisquet-Verrier et al. (1989) showed that a CS was no longer effective as a cue when the retention interval was 3 days. Therefore, the second aim of this study was to investigate a possible facilitative effect of a pretest exposure to the CS during the first $24 \mathrm{~h}$ after training. Noncued animals were compared with animals cued $5 \mathrm{~min}$ before the retention test (our usual cuing condition) after three TTIs: $10 \mathrm{~min}, 1 \mathrm{~h}$, or $24 \mathrm{~h}$.

Thus, the effect of a pretest exposure to the CS was studied after various cuing-to-test intervals (with the retention test occurring $1 \mathrm{~h}$ after training) and after various TTIs (with the cuing treatment occurring $5 \mathrm{~min}$ before testing).

\section{METHOD}

\section{Experimental Design}

This experiment corresponds to a crossed incomplete factorial design including nine groups of animals ( $n=15$ in each group), as illustrated in Table 1 . The time course of effectiveness of the cuing treatment was studied in the five groups subjected to the 1-h TTI (Table 1A): one noncued group (Group Ih-NC) and four cued groups differing from each other with respect to the length of their cuing-to-test interval-0 (Group 1h-C0), 5 (Group lh-C(5)-regular cuing condition), 10 (Group $\mathrm{lh}-\mathrm{C} 10$ ), and $20 \mathrm{~min}$ (Group $\mathrm{lh}-\mathrm{C} 20$ ). The effectiveness of a pretest exposure to the CS during the first $24 \mathrm{~h}$ was studied after three different TTIs ( $10 \mathrm{~min}, 1 \mathrm{~h}$, and $24 \mathrm{~h}$ ) and two testing conditions-noncued or cued (with cuing ending 5 min before testing)-according to a $2 \times 3$ factorial design (Table 1B). Group $\mathrm{lh}-\mathrm{NC}$ and Group $\mathrm{Ih}-\mathrm{C}(5)$ described above were subjected to the 1-h TTI, whereas Groups $10 \mathrm{~min}-\mathrm{NC}$ and $10 \mathrm{~min}-\mathrm{C}$ and Groups $24 \mathrm{~h}-\mathrm{NC}$ and $24 \mathrm{~h}-\mathrm{C}$ were subjected to the 10 -min and 24-h ITI, respectively.

\section{Subjects}

The subjects were 150 naive male Sprague-Dawley rats obtained from the Iffa-Credo rearing center, 50-57 days old and weighing $250 \mathrm{~g}$ at their arrival in the laboratory. They were housed in pairs in wire-mesh cages and had free access to food and water throughout the experiment.

\section{Table 1}

Experimental design for studying (A) the time course of effectiveness of a pretest exposure to the CS following four different cuing-to-test intervals $(5,0,10$, or $20 \mathrm{~min})$, and (B) the effect of a pretest exposure to the CS (delivered $5 \mathrm{~min}$ before testing) following three different training-to-test intervals (10 min, $1 \mathrm{~h}$, or $24 \mathrm{~h})$. Note that Groups $1 \mathrm{~h}-\mathrm{NC}$ and $1 \mathrm{~h}-\mathrm{C}(5)$ are involved in both $(A)$ and $(B)$.

\begin{tabular}{|c|c|c|c|c|}
\hline & \multicolumn{3}{|c|}{ TRAINING - TO-TEST } & INTERVAL \\
\hline & \multicolumn{2}{|c|}{$10 \mathrm{~min}$} & 1h & $24 \mathrm{~h}$ \\
\hline NON CUED & \multicolumn{2}{|c|}{$10 \mathrm{~min}-\mathrm{NC}$} & $1 \mathrm{~h}-\mathrm{NC}$ & $24 \mathrm{~h}-\mathrm{NC}$ \\
\hline CUED & \multicolumn{2}{|c|}{$10 \mathrm{~min}-\mathrm{C}$} & 1h $C(5)$ & $24 \mathrm{~h}-\mathrm{C}$ \\
\hline & \multirow{3}{*}{\multicolumn{2}{|c|}{ 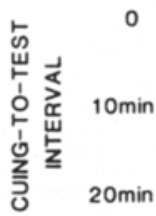 }} & $1 \mathrm{~h}-\mathrm{CO}$ & \\
\hline & & & $1 \mathrm{~h}-\mathrm{C} 10$ & \\
\hline & & & $1 \mathrm{~h}-\mathrm{C} 20$ & \\
\hline
\end{tabular}

\section{Apparatus}

Training and testing were carried out in a fully automated black Perspex Y-maze with arms $13 \mathrm{~cm}$ wide $\times 60 \mathrm{~cm}$ long $\times 38 \mathrm{~cm}$ high and a $25-\mathrm{cm}$ equilateral triangular choice area. A 40-W lamp was located at the end of each arm. The floor consisted of 3-mmdiam grids, spaced $9 \mathrm{~mm}$ apart. A shock generator (Campden Model 521S), set to deliver scrambled shock, provided the incentive for learning. Photocells placed at $1 \mathrm{~cm}$ (proximal), $11 \mathrm{~cm}$ (medial), and $30 \mathrm{~cm}$ (distal) from the entrance of each arm were connected to an Apple II microprocessor that controlled the light sequence and the length of the intertrial interval, and recorded latencies and the sequence of visited arms. The maze was housed in a darkened room adjacent to the colony room.

Cuing treatments occurred in the colony room, in a cuing box that differed from the experimental apparatus in size $(23 \times 23 \times 36 \mathrm{~cm})$ and color (beige), was covered by a removable ceiling, and equipped with a $40-\mathrm{W}$ lamp.

\section{Procedure}

The day before the beginning of the pretraining session, the rats were handled 2 at a time during a 5 -min period.

Pretraining. On Day 1, the rats, in groups of 6, were given a 15-min free exploration period in the entirely lighted maze. On Day 2, each rat was placed in the lighted maze and allowed to explore the apparatus for $5 \mathrm{~min}$.

Training. Training began on the following day (Day 3). All animals were given 15 training trials according to the following procedure. Each rat was placed in the lighted start arm of the Y-maze for $20 \mathrm{sec}$. The door closing the start arm (and used only on the first trial) was then opened, the light was turned off, and another arm was lighted. Five seconds later, an electric shock was applied to the grid floor in the entire maze, except for the terminal $30 \mathrm{~cm}$ of the lighted arm. During the first five trials, the amplitude of the electric shock was adapted for each animal just below the squeak threshold and corresponded to the minimal level for eliciting a rapid response (between 0.3 and $0.5 \mathrm{~mA}$ ). The rat had to run to the lighted arm in order to escape or avoid the footshock.

The time elapsed from the lighting of a new goal arm until the subject crossed the proximal photobeam of the initial arm was de- 
fined as the start latency. The time elapsed until the subject crossed the distal photobeam of the new goal arm was defined as the response latency. When the animal crossed the medial photobeam of an arm, that arm was considered as having been visited. An incorrect response was scored when the rat entered into one of the dark alleys before escaping into the lighted alley. Animals that failed to respond within $60 \mathrm{sec}$ were manually pushed into the lighted arm; a response latency of $60 \mathrm{sec}$ was then scored. The rat remained in the safe compartment for a 20 -sec intertrial interval during which an exit from the lighted alley led to shock. The goal alley on any given trial served as start alley for the next trial. The sequence of correct right and left turns in the Y-maze was determined according to the following pseudorandom schedule: L-L-R-L-R-R-L-RR-L-R-L-L-R-R

After completion of the 15 training trials, the rats were removed from the maze and returned to their home cages, where they remained for the time corresponding to their TTI. Each animal was then assigned to one of the nine groups on the basis of its performance during the training phase (response latency, number of errors, and number of avoidances). Animals responding with mean latencies greater than $30 \mathrm{sec}$ during the last five training trials were discarded $(n=15)$.

Cuing. Before the testing session, the animals in the cued condition were placed in the cuing box set in the colony room for a 2.5 min period. The subjects were exposed to a series of five 2-sec illuminations presented every $28 \mathrm{sec}$, similar (except for duration) to those used previously as the CS. In order to assess a possible nonspecific arousing effect of cuing on subsequent retention performance, activity demonstrated by the animals during cuing was registered: during each of the five 30 -sec periods of the cuing treatment, horizontal activity was scored $0,1,2$, or 3 according to a global evaluation of the locomotor activity level. Vertical activity, or the number of rearings, was also noted. The scores during the five 30-sec periods of cuing were summed and constituted the horizontal and vertical activity scores for each animal. At the end of the cuing treatment, the animals were either tested immediately (Group $1 \mathrm{~h}-\mathrm{C} 0$ ) or returned to their home cages for their cuing-totest interval.

Testing. At the end of their retention interval $(10 \mathrm{~min}, 1 \mathrm{~h}$, or $24 \mathrm{~h}$ ), the noncued and cued animals (except those of the C0 group) were removed from their home cages and carried in the experimenter's hand to the adjacent experimental room. They were placed directly into the lighted start arm. Twenty seconds later, the start door was opened and the animals were retrained for 25 trials in the same conditions as during the initial training, with the lighted arm positioned according to the following sequence: $L-R-R-R-L-$ L-R-L-L-L-R-L-L-R-L-R-R-R-L-L-R-R-L-R-R.

Behavioral measures. Throughout training and testing, start latencies, response latencies, and sequences of visited arms were recorded for each trial. As pointed out in a recent paper (GisquetVerrier \& Alexinsky, 1988), a real avoidance response is difficult to obtain in our training condition, considering the length of the CS-UCS interval $(5 \mathrm{sec}$ ) relative to the size of the apparatus, as well as the small number of training trials. A start latency below $5 \mathrm{sec}$ corresponded to an exit from the initial arm during the CSUCS interval. Such a response, emitted before the onset of the UCS, can roughly be assimilated to an avoidance response in a shuttlebox apparatus, was considered as an attempt to avoid, and was scored 1. A response latency less than $5 \mathrm{sec}$ permitted avoidance of the shock and was scored 2. The response latencies (after a logarithmic transformation), the number of errors, and the avoidance score were pooled in blocks of five trials for training and testing. Number of errors was very low at the end of training; therefore, this measure during retention performance was inappropriate because of a floor effect. Avoidance responses have been preferred to response latencies as an index of learning of the task because starting to move before the onset of the UCS seems to be more ap- propriate as an adaptive response than does moving faster. Furthermore, few escape responses with long latencies due to some emotional reactiveness to shock affect mean latencies more than do several avoidance responses emitted within a response time close to $5 \mathrm{sec}$. Therefore, savings in avoidance, expressed as the difference between the mean score of the first five testing trials and that of the last five training trials, served as a measure of retention (for more details, see Gisquet-Verrier \& Alexinsky, 1988).

Statistical analyses. Within-group comparisons compared performance obtained during the first five testing trials with that obtained during the last five training trials. Paired comparisons analyzed between-group differences concerning either the savings in avoidance or the avoidance scores during testing

The experiment was run over 21 consecutive days. Each day, 1 animal of each experimental condition was placed in the pretraining phase and over subsequent days was subjected to the entire procedure until the different experimental groups were completed.

\section{RESULTS}

\section{Initial Training}

An analysis of variance (repetition $\times$ group) was performed on the three blocks of five training trials among the nine groups that subsequently differed in length of TTI and in pretest treatment. This analysis revealed a significant effect of repetition on each performance measure (response latencies, errors, and avoidances; $p<.001$ in each case). There were no differences among groups or interactions between groups and repetition, regardless of the considered variable.

\section{Activity Developed During the Cuing Treatment}

Figure 1 depicts the subjects' horizontal and vertical activity during the cuing treatment. An analysis of variance for the four groups of cued animals tested $1 \mathrm{~h}$ after initial training indicated no difference for either activity measure $[F(3,56)<1$ in each case $]$. This result indicates that the different intervals of time, ranging from 37 to $57 \mathrm{~min}$ between the end of training and the beginning of cuing, did not affect the general level of activity during the cuing treatment.

In contrast, an overall analysis of variance performed on the activity scores of the three groups of animals cued $5 \mathrm{~min}$ before testing, with their retention test occurring after different TTIs (Groups 10min-C, $1 \mathrm{~h}-\mathrm{C}$, and $24 \mathrm{~h}-\mathrm{C}$ ), indicated significant differences on both horizontal $[F(2,42)$ $=11.66, p<.001]$ and vertical $[F(2,42)=17.54, p<$ $.001]$ activity. Paired comparisons performed among those three groups all indicated significant differences for both horizontal and vertical activity $(p<.049$ to $p<.001$ ). These results demonstrate a progressive decrease of activity as a function of the length of the time interpolated between training and cuing.

No significant correlation between any of the activity measures and the savings in avoidance that constituted the retention measure was obtained for any group $(.011<$ $r<.20$ ).

In all, these results seem to suggest that after initial training, there is a progressive decrease of either the animals' activity or their reactiveness to the $\mathrm{CS}$, which 


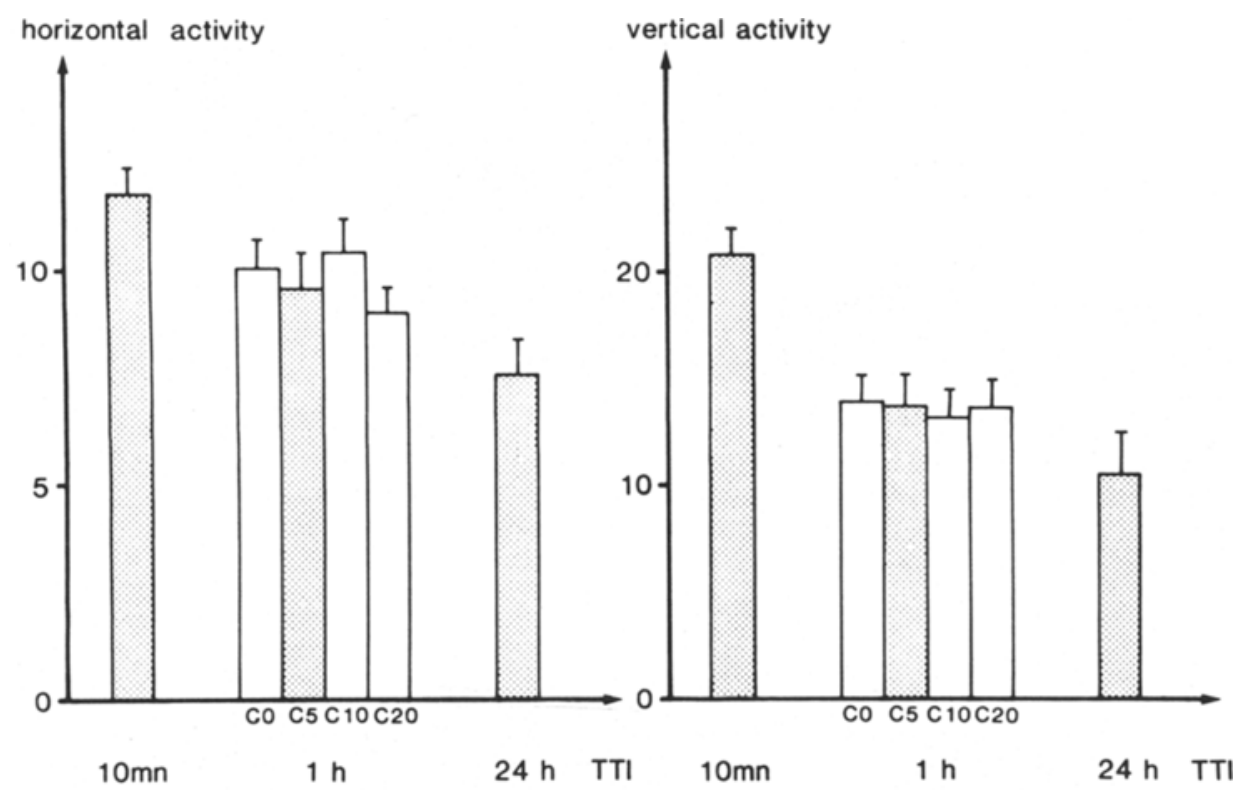

Figure 1. Mean horizontal and vertical activity scores $( \pm S E M)$ demonstrated by the animals during the 2.5-min duration of cuing, delivered before a retention test occurring $10 \mathrm{~min}, 1 \mathrm{~h}$, or $24 \mathrm{~h}$ following initial training. Dotted columns correspond to groups of animals cued $5 \mathrm{~min}$ before testing.

is not, however, related to the effect of cuing on subsequent retention performance.

\section{Time Course of Effectiveness of a Pretest Exposure to the CS After a 1-h TTI (Variable TTI)}

Figure 2 presents the mean number of avoidances during training and testing (Figure 2a) and the savings in avoidance for each of the experimental groups (Figure $2 b$ ). Within-group comparisons indicated that the animals cued 5 min before testing (Group lh-C5) demonstrated a significant improvement in avoidance performance between the end of training and the beginning of testing $[F(1,14)=$ $8.75, p<.025$ ]. Numerically, the noncued animals (Group $1 \mathrm{~h}-\mathrm{NC}$ ) exhibited a disruption of performance, but this difference fell just short of significance $[F(1,14)=4.30$, $p=.057]$. No other within-group comparison led to a significant result.

An overall analysis of variance performed on the savings in avoidance (see Figure $2 b$ ) indicated significant differences among the five groups $[F(4,70)=2.92, p<$ $.05]$. Paired comparisons showed that a pretest exposure to the CS improved retention performance, relative to the noncued animals, when cuing occurred 5 or $10 \mathrm{~min}$ before testing $[F(1,28)=12.92, p<.005$, and $F(1,28)=$ $6.07, p<.025$, respectively]. The difference between cued and noncued animals fell just short of significance when cuing was delivered immediately before testing $[F(1,28)=4.09, p=.055]$. The animals cued $20 \mathrm{~min}$ before testing did not differ significantly from the noncued animals $[F(1,28)=3.00]$. There were no significant differences among the four cued groups.
Similar analysis gave the same results when performed on the number of avoidances during the first five retraining trials (Figure 2a). No difference was found after the first block of retraining trials, which indicates that cuing primarily acted on retention performance.

These data confirm previous data obtained under similar circumstances (Gisquet-Verrier et al., 1989). As already noted, the Kamin effect is a reliable, but weak, phenomenon. A pretest exposure to the CS largely improved retention performance, particularly when delivered $5 \mathrm{~min}$ before testing. Significant improvement of performance was also obtained following a 10-min cuing-to-test interval, but not after a shorter $(0-\mathrm{sec})$ or a longer (20$\mathrm{min}$ ) interval. In all, these results confirm the facilitative effect of a pretest exposure to the CS during a 1-h delayed retention test. This effect, however, was transient.

\section{Effectiveness of Pretest Exposure to the CS During the First $24 \mathrm{~h}$ Following Initial Training (Variable TTI)}

Figure 3 shows the number of avoidances (Figure 3a) and the savings in avoidance (Figure $3 \mathrm{~b}$ ) in animals tested following a 10-min, a 1-h, or a $24-\mathrm{h}$ retention interval, with or without pretest exposure to the cuing treatment (the two groups tested after a 1-h TTI were the same as those discussed in the above section).

Within-group comparisons of the number of avoidances indicated an improvement of performance between the end of training and the beginning of retraining for the cued animals tested $1 \mathrm{~h}$ and $24 \mathrm{~h}$ after initial training $[F(1,14)$ $=8.75, p<.025$, and $F(1,14)=15.10, p<.005$, respectively]. There was no significant improvement in 


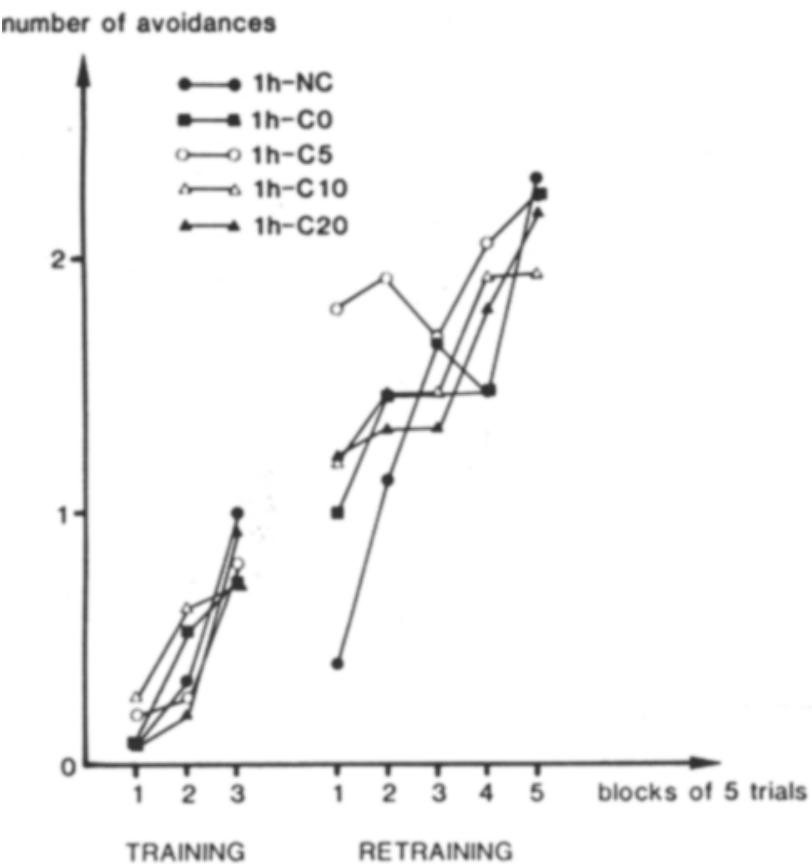

a savings in avoidances

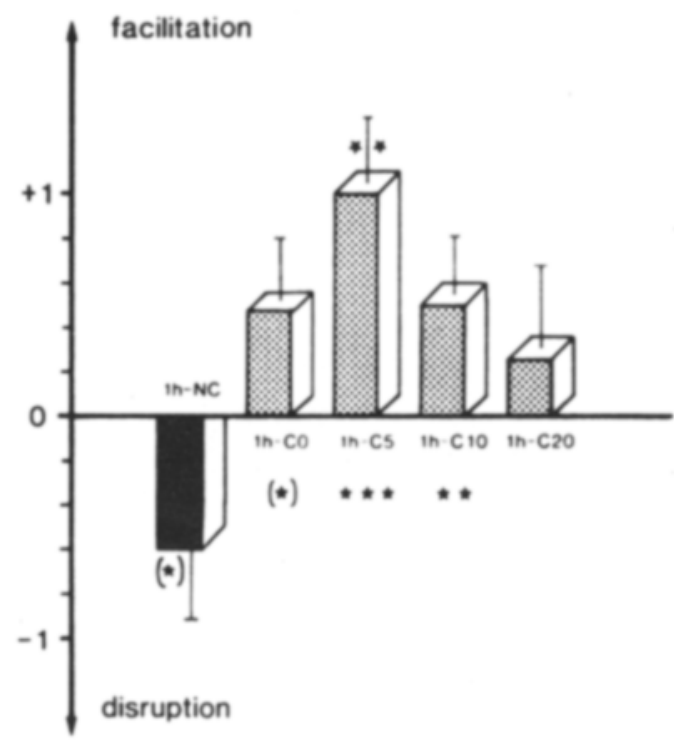

b

Figure 2. (a) Mean number of avoidance responses obtained during training and retraining (occurring $1 \mathrm{~h}$ later) for noncued animals (1h-NC) and for animals cued immediately (1h-C0), $5 \mathrm{~min}(1 \mathrm{~h}-\mathrm{C5}), 10 \mathrm{~min}(1 \mathrm{~h}-\mathrm{C10})$, or $20 \mathrm{~min}$ (1h-C20) before testing. (b) Mean $( \pm S E M)$ score of savings in avoidance (difference between the score obtained during the first five testing trials and the last five testing trials) obtained after a 1-h training-to-test interval for each experimental condition. Asterisks at the top of the columns correspond to within-group comparisons, and asterisks at the base of the columns correspond to comparisons relative to the 1h-NC group $\left(\left(^{*}\right) .05<p<.10, * * .025<p<.005, * * p<.001\right)$.

the performance of cued animals tested after a 10-min retention interval $[F(1,14)=2.05]$ and, as previously reported, the disruption of performance exhibited by the noncued animals after a 1-h TTI fell just short of significance $[F(1,14)=4.30, p=.057]$.

A two-way analysis of variance (pretest treatment $x$ length of TTI) performed on the savings in avoidance indicated a significant main effect of testing condition $[F(1,84)=16.08, p<.001]$, no significant effect of TTI $[F(2,84)=2.11]$, and no interaction between these factors $(F<1)$. In other words, these results indicate that the rats given a pretest exposure to the CS during the first $24 \mathrm{~h}$ following training performed more efficiently than the animals given no cue.

Paired comparisons of the savings in avoidance indicated that pretest cuing did not significantly improve retention performance after a $10-\min$ TTI $[F(1,28)=1.98$, $p=.17$ ]. However, the cued animals exhibited a large improvement in performance, relative to the noncued animals, when testing took place $1 \mathrm{~h}$ or $24 \mathrm{~h}$ after initial training $[F(1,28)=12.92, p<.005$, and $F(1,28)=5.14$, $p<.029$, respectively].

The results also showed that cuing acts primarily on the retention phase and not on the following reacquisition, since paired comparisons on the number of avoidances (Figure 3a) did not indicate any significant differences following the first block of testing trials.
These results indicate that the facilitative effect of a pretest exposure to the CS is not restricted to the drop in performance that corresponds to the Kamin effect (i.e., after a 1-h TTI), but can also be observed after a 24-h TTI, when control animals performed at the same level as they did at the end of training.

\section{DISCUSSION}

The present experiment confirms that after partial acquisition of a brightness-discrimination avoidance task, pretest exposure to the CS not only overcame the performance deficit normally obtained in noncued animals (Kamin effect), but induced a large improvement in retention performance (Gisquet-Verrier et al., 1989). Such an effect is relatively transient, since it did not persist over $10 \mathrm{~min}$. Furthermore, the improvement of performance resulting from a pretest exposure to the CS was not restricted to retention intervals that yielded the Kamin effect; it was also obtained after a 24-h retention interval, when the noncued animals performed at the same level as they did at the end of training.

It seems difficult to account for the facilitative effect of a pretest exposure to the CS in terms of nonspecific effects, for two main reasons. First, the pretest exposure to the CS induced a facilitative effect only when it occurred before the retention test. When delivered before 


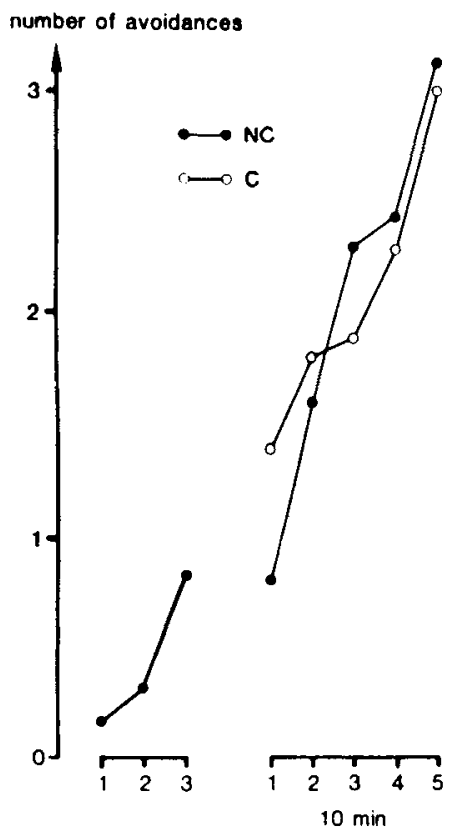

TRAINING

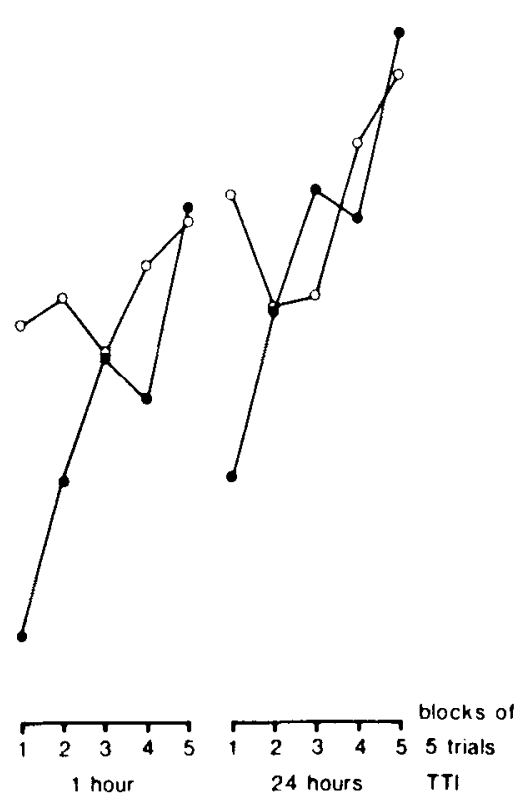

RETRAINING

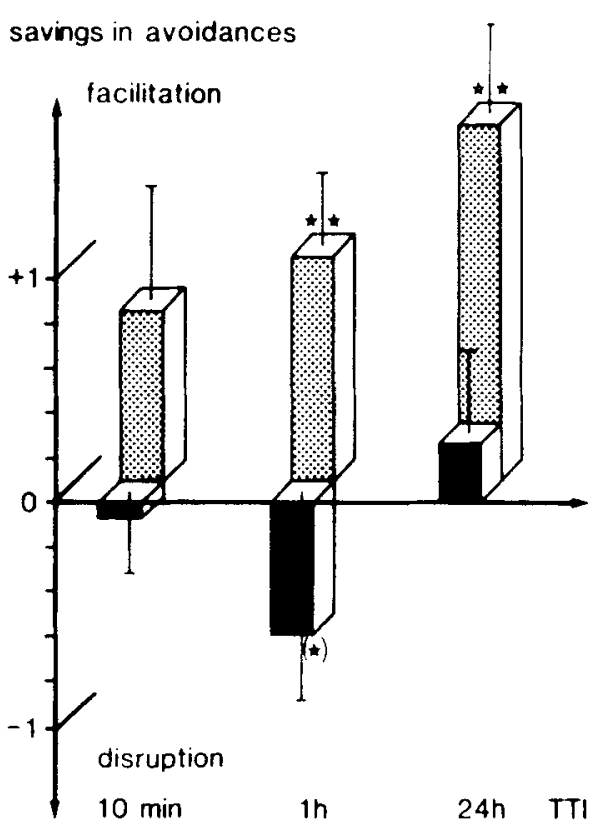

$\mathbf{a}$

Figure 3. (a) Mean number of avoidance responses obtained during training for the six experimental groups and during retraining occurring $10 \mathrm{~min}, 1 \mathrm{~h}$, or $24 \mathrm{~h}$ later for noncued $(\mathrm{NC})$ and cued $(\mathrm{C})$ animals. (b) Mean $( \pm S E M)$ score of savings in avoidance obtained for independent groups of animals tested $10 \mathrm{~min}, 1 \mathrm{~h}$, or $24 \mathrm{~h}$ following initial training. Black columns correspond to noncued animals; dotted columns correspond to cued animals. Asterisks correspond to intragroup comparisons: $* .05<p<.10$, ${ }^{* *} .025<p<.005$.

a training episode, this treatment had an opposite effect on acquisition-that is, a disruptive effect (Alexinsky, Guillemin, \& Gisquet-Verrier, 1987). Second, the effectiveness of this cue clearly depends on the duration of the retention interval. We have recently shown that this treatment did not enhance retention performance when delivered 3 or 21 days after initial training (Gisquet-Verrier et al., 1989). In our opinion, these two findings attest to the specificity of the cuing treatment. Furthermore, the facilitative effect of cuing seems not to be due to an arousing effect resulting from repetitive exposures to the light, since no correlation between retention performance and the activity demonstrated during cuing could be detected.

\section{Retrieval Versus Maturation Hypotheses}

One of the aims of this paper was to determine whether the maturation or the retrieval hypothesis would better account for the improvement of performance obtained after exposure to the CS as a pretest cue. It was assumed that if cuing acts on retrieval processes, its effectiveness would be transient (i.e., it would decline as a function of the cuing-to-test interval). The contention that the cuing effect persists during an extended period of timeas long as several days-comes primarily from studies demonstrating that cuing may induce recovery from experimental amnesia that can still be evidenced after several days (DeVietti \& Hopfer, 1974; Mactutus, Ferek, George,
\& Riccio, 1982; R. R. Miller, Ott, Beck, \& Springer, 1974; R. R. Miller \& Springer, 1972; Misanin, Miller, \& Lewis, 1968). However, forgetting resulting from experimental amnesia appears to be different from long-term forgetting. Experimental amnesia is usually produced by a brief, drastic event modifying the internal state of the subject (electroconvulsive shock, hypothermia, anoxia, etc.). Poor performance during a subsequent retention test could be due to strong alterations in the associative processes that took place during training, whereas long-term forgetting seems to be due to a progressive decrease in the strength of these associative processes. The fact that similar cue-induced enhancement of performance is obtained in both cases does not imply an identity of the underlying processes. For example, one can suggest that after experimental amnesia, cuing is able to reinstate the memory trace through a reactivation process, ruling out the retrograde effect of the amnesic treatment, whereas in the case of spontaneous forgetting, cuing acts only by inducing the reactivation of the weakened trace. Such a view would account for different lengths of cuing effectiveness related to the initial source of forgetting. Only a few studies have reported long-lasting effects of cuing after spontaneous forgetting. In two studies, retention of Pavlovian conditioning was assessed by the evaluation of the time necessary for the animals to leave the previously shocked compartment (Spear, Hamberg, \& Bryan, 1980; 
Spear \& Parsons, 1976). However, with such a measure, the cued animals exhibited good retention for several days after cuing, whereas the noncued animals demonstrated rapid forgetting, which was almost complete after 1 day. This brings into question the value of that index of performance as a retention measure and, consequently, of the interpretation of these results in terms of length of the cuing effect. Nevertheless, in another study using a oneway avoidance task, a long-lasting effect of cuing was also reported (Gordon, Smith, \& Katz, 1979). It could be suggested that the cuing in that study condition that involved exposure to the CS delivered within the training apparatus may have affected the length of the cuing effect (see also Rovee-Collier, Patterson, \& Hayne, 1985, but in human infants).

The rationale for a transient effect of cuing comes principally from numerous studies performed in our laboratory in which discrete exposure to an isolated component of the training situation has repeatedly been found to have only a transient effect on subsequent retention performance. Deweer and Sara (1984) demonstrated that after a 25-day retention interval in a food-reinforced maze task, exposure to the experimental context significantly alleviated forgetting when it was presented just prior to the retention test but not when it occurred $1 \mathrm{~h}$ or $24 \mathrm{~h}$ earlier. More recently, Dekeyne and Deweer (1990), using an interference paradigm, showed that exposure to a contextual tone enhanced retention of the task with which the tone was related when it was delivered $5 \mathrm{~min}$ before testing, but not when it was delivered $1 \mathrm{~h}$ before. Furthermore, using the same discriminative avoidance task as that used in the present study, we gave animals either pretest exposure to the experimental context or a series of five footshocks, after a 21-day retention interval. Cued rats exhibited, relative to noncued rats, a slight improvement in performance when cuing occurred immediately before testing, a significant improvement when it occurred 5 or $10 \mathrm{~min}$ before testing, and performance like that of controls when cuing occurred $20 \mathrm{~min}, 1 \mathrm{~h}$, or $24 \mathrm{~h}$ before the retention test (Gisquet-Verrier \& Alexinsky, 1987). In all, these results demonstrated that in a long-term forgetting paradigm, as well as in an interference paradigm (where the improvement of performance induced by pretest cuing is widely accepted as resulting from an enhancement of retrieval processes), short-lasting effects were repeatedly obtained.

The present experiment indicates a facilitative effect of cuing for a 1-h delayed retention test, with significant differences between cued and noncued animals only when cuing occurred 5 or $10 \mathrm{~min}$ before testing. These results suggest that cuing effectiveness increases from 0 to $5 \mathrm{~min}$ and then progressively decreases from 10 to $20 \mathrm{~min}$. Such a finding does not conclusively support the assumption that exposure to the CS could accelerate an elaborative process (maturation or consolidation), leading to LTSI, for which a longer lasting effect (at least more than few minutes) would be expected. The similarity between the time course of effectiveness obtained for cuing 21 days after initial training (Gisquet-Verrier \& Alexinsky, 1987) and that obtained in the present study, $1 \mathrm{~h}$ after training, suggests similar processes. Furthermore, this similarity also seems to preclude an interpretation of the present data as depending on the length of the training-to-cue interval (see R. R. Miller, Greco, Marlin, \& Balaz, 1985), since after a 21-day TTI, differences in training-to-cue intervals appeared negligible relative to those of the cuing-totest intervals. Therefore, we tentatively conclude that a pretest exposure to the CS delivered shortly after training acts in the same way as effective cuing long after training does-that is, by transiently enhancing the retrieval process.

\section{Effectiveness of the CS During Short TTIs}

The present results confirm that a pretest exposure to the CS markedly enhances subsequent retention performance when delivered $1 \mathrm{~h}$ after training, and they further indicate that this facilitative effect can also be obtained after a 24-h retention interval, when control animals performed at the same level as they did at the end of training. Therefore, the effectiveness of this cuing treatment seems not to depend on a particular state that prevailed in the animals $1 \mathrm{~h}$ after training, but rather seems to be related to particular characteristics of the memory trace shortly after training. However, when delivered before a 10-min TTI, cuing had no significant effect on performance. It must be emphasized that under those circumstances, cuing began only $2.5 \mathrm{~min}$ after the end of training. As illustrated in Figure 1, at that time the animals demonstrated a particularly high level of activity that might have reduced their attention to the stimuli delivered during cuing, accounting for the lack of an effect. Another possibility is that the initial processing of information promoted by training may have continued during the first few minutes, making cuing less effective than when it occurred later.

\section{The CS as a Retrieval Cue}

As noted by Spear (1978), despite the fact that a conditioned or discriminative stimulus must have the potential to activate a memory, instances of facilitative effects when such stimuli are used as retrieval cues are rare in the literature. However, there are some studies that have demonstrated that exposure to the CS may be used as a retrieval cue. Exposure to the CS may induce a memory restoration when delivered after an electroconvulsive shock treatment (Gordon \& Mowrer, 1980). A pretest exposure to the positive $(\mathrm{S}+)$ or to the negative (S-) CS may reinstate the initial sharp generalization gradient between these two stimuli established $24 \mathrm{~h}$ earlier (Moye \& Thomas, 1982). It has also been demonstrated that exposure to the blocked CS or to the overshadowed CS reversed blocking or overshadowing (Balaz, Gutsin, Cacheiro, \& Miller, 1982; Kasprow, Cacheiro, Balaz, \& Miller, 1982).

Obviously, in the Pavlovian paradigm, exposure to the CS in the absence of the UCS previously paired with the $\mathrm{CS}$ results in a decrement of the conditioned response, 
or "extinction." There is, however, some evidence that the occurrence of a CS unaccompanied by the UCS does not always yield extinction. Extinction operations, at least in the case of aversive learning, may produce the opposite result-namely, an increment in response strength. Such a paradoxical enhancement of fear-related responses subsequent to an extinction procedure has been noted in human studies investigating the rationale of therapeutic studies that involve confronting patients with fear-evoking stimuli (see Eysenck, 1967; B. V. Miller \& Levis, 1971; Reynierse, 1966). A similar phenomenon has also been reported in the experimental literature with animals (see Napalkov, 1963; Rohrbaugh \& Riccio, 1970; Rohrbaugh et al., 1972).

Gordon et al. (1979) obtained enhanced avoidance responding in rats after an exposure to the CS delivered in the training apparatus. Those authors postulated that such a paradoxical enhancement may be due to memory reactivation induced by cuing and to a strengthening of the memory trace, presumably resulting from rehearsal of information (Gordon \& Feldman, 1978). Our results, which demonstrate that some time must elapse after the end of cuing in order for the treatment to be significantly effective, can be interpreted as supporting the view that cuing may have a twofold consequence. Aside from a primary effect of reactivation, cuing may also induce a renewal of information processing that takes some time. This would explain why, after cuing, performance is not only equivalent to that obtained during LTSI, but is even better (Gisquet-Verrier et al., 1989). However, the transience of the facilitative effect of cuing does not allow us to assimilate this process to a consolidation process that would strengthen the memory trace more durably.

The fact that a pretest exposure to the CS delivered soon after training induced an enhancement of retention performance rather similar to that obtained (using the same task without cuing) after a 3-day TTI supports the assumption that this level of performance may reflect what has really been learned during the acquisition phase, but which was not readily accessible in control animals shortly after training (Gisquet-Verrier et al., 1989). According to the multidimensional concept of memory, the memory trace might be viewed as a collection of memory attributes, each of which is the internal representation of a distinct training event (see Spear, 1978; Underwood, 1969). It is further suggested that each individual attribute may develop rather independently over time according to a concept close to McGeoch and Irion's (1952) differential forgetting hypothesis. We have already presented evidence that LTSI may result from the progressive dissipation, due to differential forgetting, of the "negative factors," the nature of which remains unknown. Such a position is close to that held by R. R. Miller, Kasprow, and Schachtman (1986), who considered that "the superior retention seen after reminiscence reflects information that existed within the subject since the time of initial acquisition even though it was not evident at any time prior to reminiscence" (p. 189). In the same way, it can be hypothesized that a pretest exposure to the CS, when delivered shortly after training, enhances retention by promoting the reactivation of the target memory without reactivating the negative factors that depress the performance in noncued animals directly placed in the experimental situation.

\section{Decrease Over Time of the CS as an Effective Retrieval Cue}

An important point to emphasize is that in every case where exposure to the CS has been shown to influence subsequent performance, cues were always presented relatively soon after training: 0-40 min for Reynierse (1966); 3-5 min for Napalkov (1963); 5-30 min for Rohrbaugh and Riccio (1970); 1-6 min for Rohrbaugh et al. (1972); 1 day for Kasprow et al. (1982), Balaz et al. (1982), and Moye and Thomas (1982); and 3 days for Gordon et al. (1979). Previous results of our own have demonstrated that the cuing effectiveness of a pretest exposure to the CS significantly decreases between $1 \mathrm{~h}$ and 21 days (Gisquet-Verrier et al., 1989). There are some arguments in the literature that memory for a specific CS diminishes over time. Thomas and Riccio (1979) indicated that although only the original CS produced blocking after a 1-day retention interval, both the original and a novel CS resulted in blocking after a 21-day retention interval, suggesting that memory for specific attributes of the CS diminishes as a function of time. Hendersen, Patterson, and Jackson (1980) showed that avoidance behavior is enhanced by a CS that has been paired a few times with a different aversive UCS than the one used in avoidance training. When the number of initial pairings increases, facilitation decreases, demonstrating that the animals learned the specificity of the UCS. However, such an attenuation effect was not obtained after a 45-day retention interval, indicating some forgetting of the outcome that was predicted by the CS. Both of these studies indicated that some aspects of the CS (its precise characteristics or its relationship with other information) may be forgotten over time. Such a weakening of memory about the CS's features could explain the decrease over time of its effectiveness as a cue, exposure to the $\mathrm{CS}$ no longer being able to trigger the reactivation of the memory trace and, more particularly, of the target memory.

In all, these results establish the critical importance of the CS attribute(s) in the memory trace shortly after training. The fact that the importance of those attributes does not persist long after initial training and that other attributes gain weight (Gisquet-Verrier et al., 1989) strongly suggests that memory attributes are reorganized over time.

\section{REFERENCES}

Alexinsky, T., Guillemin, C., \& Gisquet-Verrier, P. (1987). Ptetest cueing: Arousal or specific information? Behavioural Brain Research, 26, 201-202.

Balaz, M. A., Gutsin, P., Cacheiro, H., Miller, R. R. (1982). Blocking as a retrieval failure: Reactivation of associations to a blocked stimulus. Quarterly Joumal of Experimental Psychology, 34B, 99-113.

DEKEYNE, A., \& DEWEER, B. (1990). Interaction between conflicting 
memories in the rat: Contextual pretest cuing reverses control of behavior by testing context. Animal Learning \& Behavior, 18, 1-12.

DeVIETTI, T. L., Hopfer, T. M. (1974). Complete amnesia induced by $\mathrm{ECS}$ and complete recovery of memory following reinstatement treatment. Physiology \& Behavior, 12, 599-603.

DeWeER, B., \& SARA, S. J. (1984). Background stimuli as a reminder after spontaneous forgetting: Role of duration of cuing and cuing-test interval. Animal Learning \& Behavior, 12, 238-247.

Deweer, B., Sara, S. J., \& Hars, B. (1980). Contextual cues and memory retrieval in rats: Alleviation of forgetting by a pretest exposure to background stimuli. Animal Learning \& Behavior, 8, 265-272.

EYSENCK, H. J. (1967). Single-trial conditioning, neurosis and the Napolkov phenomenon. Behavioral Research \& Therapy, 5, 63-65.

Gatti, S. V., Pais, N., \& WeEks, J. R. (1975). Effects of reinstatement procedures on retention of differential appetitive responding. Bulletin of the Psychonomic Society, 6, 57-60.

Gisquet-VerRIER, P., \& AlexinsKy, T. (1986). Does contextual change determine long-term forgetting? Animal Learning \& Behavior, 14, 349-358.

Gisquet-VerRIER, P., \& AleXINSKy, T. (1987). Time-dependent modification of the memory trace evidenced by pre-test cuing in rats. Society for Neuroscience Abstracts, 13, 1316.

Gisquet-Verrier, P., \& AleXinsKy, T. (1988). Time-dependent fluctuations of retention performance in an aversively motivated task. Animal Learning \& Behavior, 16, 58-66.

Gisquet-Verrier, P., Dekeyne, A., \& Alexinsky, T. (1989). Differential effects of several retrieval cues over time: Evidence for time-dependent reorganization of memory. Animal Learning \& Behavior, 17, 394-408.

Gordon, W. C., \& Feldman, D. T. (1978). Reactivation-induced interference in a short-term retention paradigm. Learning \& Motivation, 9. 164-178.

Gordon, W. C., \& Mowrer, R. R. (1980). An extinction trial as a reminder treatment following electroconvulsive shock. Animal Learning \& Behavior, 8, 363-367.

Gordon, W. C., Smith, G. J., KATZ, D. S. (1979). Dual effects of response blocking following avoidance learning. Behavioral Research \& Therapy, 17, 479-487.

Hendersen, R. W., Patterson, J. M., \& Jackson, R. L. (1980). Acquisition of instrumental behavior by a cue-signaling airblast: How specific are conditioned anticipations? Learning \& Motivation, 11, 407-426.

HUPPERT, F. A., \& Deutsch, J. A. (1969). Improvement in memory with time. Quarterly Journal of Experimental Psychology, 21, 267-271.

KAMIN, L. J. (1957). The retention of an incompletely learned avoidance response. Joumal of Comparative \& Physiological Psychology, 50, 457-460.

Kasprow, W. J., Cacheiro, H., Balaz, M. A., Miller, R. R. (1982). Reminder-induced recovery of associations to an overshadowed stimulus. Learning \& Motivation, 13, 155-166.

Mactutus, C. F., Ferek, J. M., George, C. A., \& Riccio, D. C. (1982). Hypothermia-induced amnesia for newly acquired and old reactivated memories: Commonalities and distinctions. Physiological Psychology, 10, 79-95.
McGeoch, J. A., \& IRION, A. L. (1952). The psychology of human learning. New York: Longmans.

Miller, B. V., \& Levis, D. J. (1971). The effects of varying shor visual exposure times to a phobic test stimulus on subsequent avoidance behavior. Behavioral Research \& Therapy, 9, 17-21.

Miller, R. R., Greco, C., Marlin, N. A., Balaz, M. A. (1985). Retroactive interference in rats: Independent effects of time and similarity of the intervening event with respect to acquisition. Quarterly Journal of Experimental Psychology, 37B, 81-100.

Miller, R. R., Kasprow, W. J., Schachtman, T. R. (1986). Retrieval variability: Sources and consequences. American Journal of Psychology, 99, 145-218.

Miller, R. R., Ott, C. A., Beck, A. M., Springer, A. D. (1974). Appetitive memory restoration after electroconvulsive shock in the rat. Journal of Comparative \& Physiological Psychology, 87, 717-723.

Miller, R. R., \& SPRINGER, A. D. (1972). Induced recovery of memory in rats following electroconvulsive shock. Physiology \& Behavior, 8, 645-651.

Misanin, J. R., Miller, R. R., \& Lewis, D. J. (1968). Retrograde amnesia produced by electroconvulsive shock after reactivation of a consolidated memory trace. Science, 160, 554-555.

Moye, T. B., \& Thomas, D. R. (1982). Effects of memory reactivation treatments on postdiscrimination generalization performance in pigeons. Animal Learning \& Behavior, 10, 159-166.

NAPALKOV, A. V. (1963). Information process of the brain. In N. Wiener \& J. P. Schade (Eds.), Progress in brain research: Nerve, brain and memory models (Vol. 2, pp. 59-69). Amsterdam: Elsevier.

REYNIERSE, J. H. (1966). Effects of CS only trials on resistance to extinction of an avoidance response. Joumal of Comparative \& Physiological Psychology, 61, 156-158.

Rohrgaugh, M., \& Riccio, D. C. (1970). Paradoxical enhancement of learned fear. Journal of Abnormal Psychology, 75, 210-216.

Rohrbaugh, M., Riccio, D. C., ARThur, A. (1972). Paradoxical enhancement of conditioned suppression. Behavioral Research \& Therapy, 10, 125-130.

Rovee-Collier, C., Patterson, J., \& Hayne, H. (1985). Specificity in the reactivation of infant memory? Developmental Psychobiology, 18, 559-574.

SPEAR, N. E. (1978). The processing of memories: Forgetting and retention. Hillsdale, NJ: Erlbaum.

Spear, N. E., Hamberg, J. M., \& Bryan, R. (1980). Forgetting of recently acquired or recently reactivated memories. Learning \& Motivation, $11,456-475$.

Spear, N. E., \& Parsons, P. (1976). Analysis of a reactivation treatment: Ontogeny and alleviated forgetting. In $\mathbf{R}$. Davies \& W. Roberts (Eds.), Coding processes in animal memory (pp. 135-165). Hillsdale, NJ: Erlbaum.

Thomas, D. A., \& Riccio, D. C. (1979). Forgetting of a CS attribute in a conditioned suppression paradigm. Animal Learning \& Behavior, 7, 191-195.

UNDERWOOD, B. J. (1969). Attributes of memory. Psychological Review, 76, 559-573.

(Manuscript received March 29, 1989; revision accepted for publication August 17, 1989.) 